\title{
Total Electron Content response to Geomagnetic Activity over Five African Equatorial and Low Latitude Stations
}

\author{
Abdulrahim R.B. ${ }^{1}$, Adeniyi J.O. ${ }^{2}$, Joshua B.W. ${ }^{3}$ \\ ${ }^{1}$ National Space Research and Development Agency, Abuja, Nigeria \\ ${ }^{2}$ Landmark University, Omu Aran, Kwara State Nigeria \\ ${ }^{3}$ Department of Physics, Kebbi State University of Science and Technology, \\ Aliero, Kebbi State, Nigeria \\ E mail (bourlarnley@gmail.com).
}

Accepted: 30 April, 2020

\begin{abstract}
An investigation on the response of the ionosphere to three geomagnetic storms (two strong (Dst<-100 nT, and one moderate (Dst<-50 nT) of March 17-18. June 01, and December 7-8,, 2013 has been made. The study was carried out using the total electron content (TEC) data derived from the global positioning system (GPS) receivers located at five African equatorial and low latitude stations (Toro, Mbar, Mal2, Dodm and Zamb). The stations fall between geomagnetic Latitude $0.95^{\circ} \mathrm{S}$ and $26.25^{\circ} \mathrm{S}$ and are located in the southern hemisphere. The quiet time analyses of the TEC profiles for each stations were first of all investigated using the averaged values of TEC for the five quietest days of the months in which the geomagnetic storms occurred. Results from the study show a significant variation of TEC during the disturbed days compared to those of the quiet time period. The geomagnetic storm results show prominent cases of day and night time enhancement in TEC during the main and recovery phases of the storms with percentage deviations ranging from 30 $112 \%$. Furthermore, a well -defined double peak of ionization was observed during the main phase of strong geomagnetic storm of June 01,2013 event particularly at Dodm $\left(16.10^{\circ} \mathrm{S}\right)$ and Zamb $\left(26.25^{\circ} \mathrm{S}\right)$. The enhancement in TEC is indicative of the effect of the prompt penetration electric fields and the enhanced equatorial fountain.
\end{abstract}

(c) 2019 BBSCS RN SWS. All rights reserved

Key Words: Geomagnetic storm; TEC; equatorial ionosphere; EXB force; electric field; Ionization.

\section{Introduction}

Geomagnetic storms are temporary disturbances in the earth's magnetic field that has its origin from the sun through the interplanetary medium and the effects are seen on the earth. A geomagnetic storm is characterized by a sudden decay in the $\mathrm{H}$ component of the magnetic field and usually last for up to one to a few hours and its subsequent growth (Tsurutani and Gonzalez, 1997; Melony et al., 2005 Reeve, 2010). During this period, the direction of the interplanetary magnetic field (IMF Bz) from its usual northward direction changes to the southward direction (Reeve, 2010). The modification in the orientation of the Bz gives room for the interaction of the earth's magnetic field and solar ejections from the sun through high energy transfer to the earth's magnetosphere (Dungey, 1961; Gonzalez and Tsurutani 1987; Gonzalez et al., 1994; Tsurutani and Gonzalez, 1997). The value of the IMF $\mathrm{Bz}$ attained during this period will determine the intensity of the storm to be expected (Shweta et al, 2012).

A typical geomagnetic storm event is categorized into three phases; the initial phase, the main phase and the recovery phase (Adeniyi 1986; Campbell, 2003).The initial phase of a geomagnetic storm is characterized by a sudden increase in the $\mathrm{H}$ component of the magnetic field (Kamide et al, 1998), which is manifested in the increase of the disturbance storm time (Dst) value .This usually precedes the arrival of a fast moving solar wind plasma that results in shock wave at the magnetosphere (Rostoker and Falthammar,1967; Campbell 2003). The disturbance storm time index (Dst) is used to monitor the depression in the $\mathrm{H}$ component caused by the ring current that surrounded the earth in a westward direction (Kamide et al, 1998; Buosanto, 1999). This is also a general and common means of defining the intensity of a geomagnetic storm by taking the minimum value of the Dst recorded during the entire period the storm event lasted. (Gonzalez et al, 1994). It is important to note that not all storms start suddenly; some could come in a gradual way while others could come as sudden storm commencement (Akasofu, 1965; Joselyn and Tsurutani, 1990; Campbell 2003; Mendillo, 2006). Therefore, a typical geomagnetic storm can be described as either sudden storm commencement (SSC) or gradual
Storm Commencement (GSC). A typical geomagnetic storm has three phases. The main phase is seen when there is gradual depression in the horizontal component of the Magnetic field $(\mathrm{H})$ over a period of time and the Dst attaining its minimum value. This is followed by a gradual but consistent (most times) rise in the $\mathrm{H}$ component and the Dst also returns to its former state known as the recovery phase. The geomagnetic storms, according to Loewe and Prolss (1997), is broadly classified into three 3 categories; moderate storms $(-100 \mathrm{nT}<$ Dst $<-50 \mathrm{nT})$, strong storms $(-200 \mathrm{nT}<\mathrm{Dst}-100 \mathrm{nT})$ and severe storms $(-350 \mathrm{nT}<\mathrm{Dst}-200 \mathrm{nT})$ depending on the level of depression of the Dst value.

The ionosphere by definition is the upper region of the atmosphere that allows propagation of radio waves over a long distance because of the presence of electron and charged particles in the region. The equatorial and low latitude region of the ionosphere are mainly governed by the zonal electric field during geomagnetically quiet conditions. This usually leads to the formation of equatorial ionization anomaly in the region (EIA). Therefore, it could be said that the disturbance electric field plays an important role in the variations observed at the equatorial and low latitude regions during storm time. The EIA is the occurrence of two enhanced peaks/crests of ionization at the equatorial/low latitude ionosphere, with one peak of ionization forming on either side of the magnetic equator and depletion in the electron density at the magnetic equator (Appleton, 1946). The formation of the EIA can be explained in terms of $\mathrm{E} \times \mathrm{B}$ upward drift of the ionization. Photoionization from extreme ultraviolet solar radiation plays a great role in the production of electrons while transport is dominated by neutral wind and equatorial fountain. This has been shown to enhance the background electron density leading to the formation of equatorial anomaly (Hanson and Moffett, 1966; Balan and Bailey, 1995; Henderson and Swenson, 2005; Chakraborty and Hajra, 2009; Adeniyi et al., 2010)

Geomagnetic storms have been established to have adverse effects on certain ground based systems, such as power grids, pipelines rail systems etc. (NRC, 2008). The study of the response of ionosphere to various categories of geomagnetic storm is quite paramount in mitigating the adverse effects of these events on these ground base systems as well as our space-based assets. 
Therefore, understanding the ionospheric morphology during both quiet and disturbed conditions is quite important for effective prediction and signal transmission. The total electron content is an important parameter in the study of response of the ionosphere to different space weather conditions. It has become a proxy for the study and probing of the ionosphere, and as a result, several authors have employed its use (Jakowski, 1996; Lu, et al., 1998). The ionospheric total electron content is the total number of electrons in a tube of $1 \mathrm{~m}^{2}$ cross section extending from the receiver to the satellite. Transmissions from the GPS navigation satellite is an established source of most experimental measurement and this has been employed by several authors over the years (Jakowski, 1996; Lu, Richmond and Roble, 1998; DasGupta, 2007; Wang, 2008; Rakhee Malik et al., 2010; Oladipo and Schuler 2012; Olwendo et al., 2012; Adeniyi et al., 2014; Rabiu, et al., 2014). This work therefore seeks to investigate response of TEC to three Geomagnetic storm events at five stations in the African sector. The result obtained will be very helpful in future predictions and modelling of the ionosphere over Africa.

Table 1. The List of Stations used and its coordinate

\begin{tabular}{|c|c|c|c|c|c|}
\hline & \multicolumn{2}{|c|}{$\begin{array}{c}\text { Geog. } \\
\text { Coordinate }\end{array}$} & \multicolumn{2}{|c|}{$\begin{array}{l}\text { Geomag. } \\
\text { Coord. }\end{array}$} \\
\hline $\begin{array}{l}\text { Stations/ } \\
\text { Country }\end{array}$ & Code & $\begin{array}{l}\text { Lat. } \\
(0)\end{array}$ & $\begin{array}{l}\text { Long. } \\
(0)\end{array}$ & $\begin{array}{l}\text { Lat. } \\
(0)\end{array}$ & $\begin{array}{l}\text { Long. } \\
(0)\end{array}$ \\
\hline $\begin{array}{c}\text { Toro } \\
\text { (Nigeria) }\end{array}$ & Cggn & 10.12 & 9.41 & -0.95 & 81.38 \\
\hline $\begin{array}{l}\text { Uganda } \\
\text { (Mbarara) }\end{array}$ & Mbar & -0.65 & 30.67 & -10.25 & 102.36 \\
\hline $\begin{array}{l}\text { Kenya } \\
\text { (Malindi) }\end{array}$ & Mal2 & -3 & 40.19 & -12.43 & 111.86 \\
\hline $\begin{array}{c}\text { Tanzania } \\
\text { (Dodoma) }\end{array}$ & Dodm & -6.2 & 35.8 & -16.1 & 106.77 \\
\hline $\begin{array}{l}\text { Zambia } \\
\text { (Lusaka) }\end{array}$ & Zamb & -15.25 & 28.27 & -26.25 & 98.37 \\
\hline
\end{tabular}

Table 2. List of storms and Duration of occurrence of the Main Phase

\begin{tabular}{c|l|c|c}
\hline S/N & Storm Event & Min. Dst (nT) & $\begin{array}{c}\text { Duration of } \\
\text { Main Phase(Hrs) }\end{array}$ \\
\hline 1 & March 17-18 & -132 & 15 \\
\hline 2 & Jun-01 & -119 & 8 \\
\hline 3 & Dec-08 & -66 & 7 \\
\hline
\end{tabular}

\section{Data and method of Analysis}

The ionospheric parameter used for this study is the total electron content obtained from some ground-based GPS receivers at five (5) stations located within the African sector. The stations range between geomagnetic latitude $0.95^{\circ} \mathrm{S}$ to $26.25^{\circ} \mathrm{S}$ as shown in Table 1. The geomagnetic coordinates of the stations used were calculated using a model developed by the UK solar system Data Centre (UKSSDC) and can be obtained from http://www.ukssdc.ac.uk/cgi-bin/wdec1/coordcnv.pl. The GPSTEC data were obtained from both the database of the International GNSS Service (IGS) (ftp://garner.ucsd.edu) and the African Geodetic Reference frame (AFREF) networks. The TEC data as obtained from the GPS measurements comes in Rinex format, Receiver Independent Exchange format. The slant TEC is then processed using a GPS-TEC processing software developed by Dr Gopi S. Krishna at the institute for Scientific Research, Boston College, USA. This software batch processes the input Rinex files by reading the satellite bias using the differential code bias (DCB) IGS code files to remove the receiver bias giving the output as the vertical TEC values. The interplanetary parameters used in characterising each geomagnetic storm consists of the hourly values of Dst, $\mathrm{Kp}, \mathrm{AE}$ and $\mathrm{IMF} \mathrm{Bz}$ obtained from the NASA's Omniweb data explorer website (http://omniweb.gsfc.nasa.gov/form/dx1.html) .

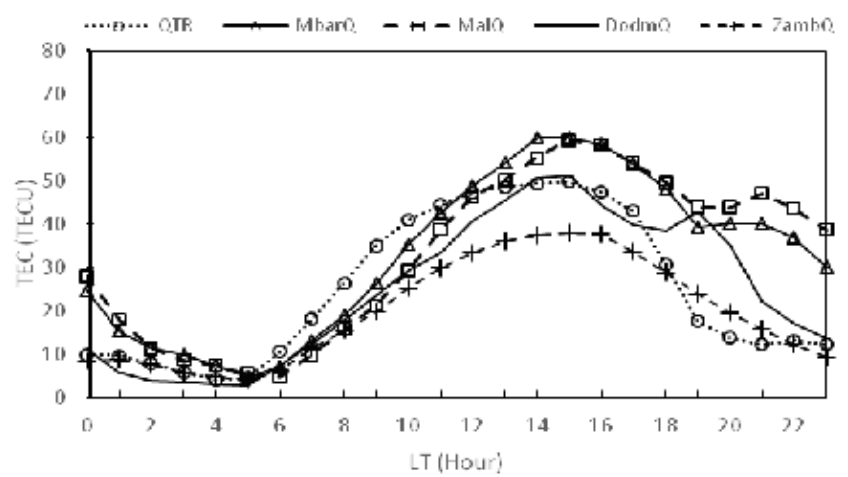

Figure 1(a) Mean diurnal Variation of TEC for the 5 most magnetically quiet days of March 2013

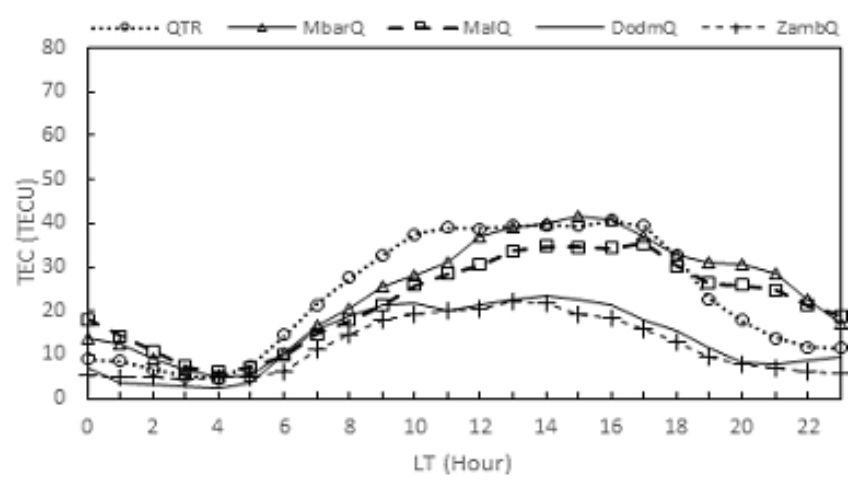

Figure 1(b) Mean diurnal Variation of TEC for the 5 most magnetically quiet days of June, 2013

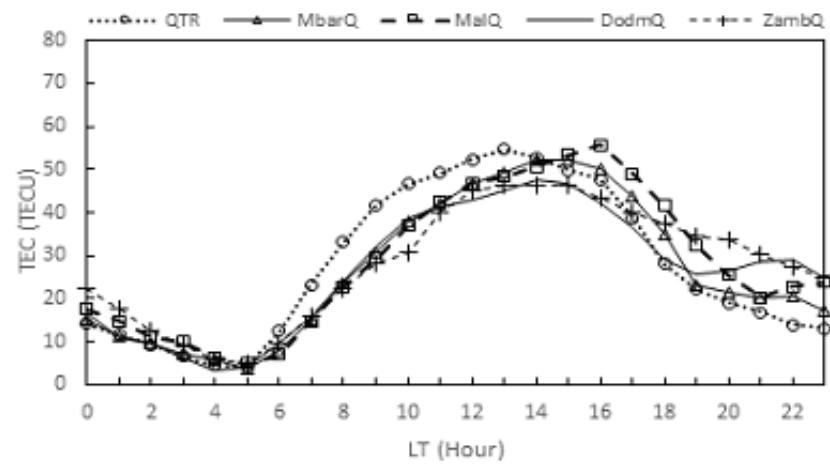

Figure 1(c) Mean diurnal Variation of TEC for the 5 most magnetically quiet days of December, 2013

Three geomagnetic storm events were considered in this study, the list of these storm events and the minimum values of the Dst index attained during each event is shown in Table 2. The data sets used were selected in a way to cover two geomagnetically quiet days before the geomagnetic storm event.

The average values of TEC for the ten most magnetically quiet days of the month displayed by the World Data centre for geomagnetism (WDC), Kyoto, Japan (website: http://wdc.kugi.kyoto-u.ac.jp/cgi-bin/qddays-cgi), were used to study the quiet time morphology of the TEC. This was used to determine the magnitude of deviation of the TEC during the geomagnetic storms. Percentage deviations in TEC during each phase of the geomagnetic storms were computed using the relationship in equation 1 ;

$$
T E C=\frac{D T E C-Q T E C}{Q T E C} \times 100[\%]
$$

Where $\boldsymbol{T E} \boldsymbol{C}=$ Total Electron Content

DTEC $=$ Disturbed day TEC and

QTEC $=$ Quiet day TEC 


\section{Results}

\subsection{Diurnal Variation of TEC during the geomagnetically quiet days}

Figure 1 shows the plots of the mean diurnal variation of TEC at five stations for the months of March (a), June (b) and December (c) for ten most magnetically quiet days in 2013. These three months represent March equinox, June (winter) solstice and December (summer) solstice, respectively. Observations from these figures reveal the occurrence of the pre-sun rise minimum for all stations occurring at around $0500 \mathrm{LT}$; higher ionization during the build-up/pre-noon period (0500-1100 LT) at Toro, i.e. QTR $\left(0.95^{\circ} \mathrm{S}\right.$ geomagnetic latitude), during the three months While the daytime TEC peak values were recorded at Mbar (Lat $\left.10.25^{\circ} \mathrm{S}\right)$ and $\mathrm{Mal} 2\left(12.43^{\circ} \mathrm{S}\right)$ during the post-noon period (1300$1600 \mathrm{LT})$, the minimum daytime values were recorded at Zamb $\left(26.25^{\circ} \mathrm{S}\right)$. This is indicative of the movement of ionization from the equatorial region to higher latitudes by the fountain effect during the daytime.

A closer look at the figure also reveals a lower rate of ionization in the month of June for all the stations with a difference that is greater than 10 TECU when compared with those observed in March and December. Results from this Figure further reveals the occurrence of post sunset enhancement at Dodm at $1900 \mathrm{LT}$ and a clear cut night time enhancement around $1900-2200 \mathrm{LT}$ at $\mathrm{Mbar}\left(10.25^{\circ} \mathrm{S}\right)$ and Mal2 $\left(12.43^{\circ} \mathrm{S}\right)$ in the month of March and June (Fig. 1a and 1b). Figure 1 also shows higher TEC night time values in these two stations until the presunrise period (0500 LT), when minimum TEC values were recorded at all stations. These night time TEC enhancements, were also observed at all stations around 2000-2300 LT, but were relatively higher at Zamb $\left(26.25^{\circ} \mathrm{S}\right)$ and Dodm $\left(16.1^{\circ} \mathrm{S}\right)$ during December (Fig. 1c). Averagely, while higher night time TEC values were seen in the month of December (summer solstice) at all stations compared to other months, the Peak values for the night-time were observed at Mal2 $\left(12.43^{\circ} \mathrm{S}\right)$ during the month of March.

\subsection{Geomagnetic Storm Effects}

\subsubsection{TEC response to the geomagnetic Storm event of 17-18 March 2013}

Figure 2(a) is a plot showing the variation from top to bottom: the IMF Bz, AE, Dst and Kp-index during the geomagnetic storm of 17-18 March, 2013. The plots span from 15 - 20 March, 2013. Figure 2(b) is a plot of the diurnal variation of TEC for the average quiet days and the disturbed period. Each panel represents TEC variation for all the stations used in this study from top to bottom: Toro $\left(0.95^{\circ} \mathrm{S}\right)$, Mbar $\left.10.25^{\circ} \mathrm{S}\right)$, Mal2 $\left(12.43^{\circ} \mathrm{S}\right)$, Dodm $\left(16.10^{\circ} \mathrm{S}\right)$ and $\mathrm{Zamb}\left(26.25^{\circ} \mathrm{S}\right)$. A fluctuation in the direction of the IMF $\mathrm{Bz}$ was seen from around 00 UT on March $16^{\text {th }}$ in figure $2 \mathrm{a}$ and this continued till 00UT on March $17^{\text {th }}$ when IMF Bz turned northward for few hours, leading to a sudden rise in the Dst, thus indicating an initial phase with a sudden storm comment (SSC). This was followed by a sharp southward turning of the IMF Bz from a value of about $3 \mathrm{nT}$ to a minimum value of about $13 \mathrm{nT}$ around 0800UT. The Dst values drastically reduced to a minimum value of about $-132 \mathrm{nT}$, both $\mathrm{AE}$ and $\mathrm{Kp}$ indices attained their maxima around this time on the $17^{\text {th }}$ of March. This shows that the main phase of this storm occurred on the $17^{\text {th }}$ March and lasted for about 15 hours. The characteristics exhibited by this geomagnetic storm is indicative of a strong storm with a sudden commencement (SC). The initial phase of the storm occurred during the build-up period of ionization, while the main phase spanned through the day time to the post-midnight period. An enhancement in the $\mathrm{AE}$ index and the planetary $\mathrm{K}$ index was also observed during the main phase $(\mathrm{AE}=1900 \mathrm{nT}, \mathrm{Kp}=70)$. The recovery period began during the post sunset period of $17^{\text {th }}$ and continued through March 18-20.
The response of ionospheric TEC to the geomagnetic storm of March 17-18, 2013 (black dashed line) is shown in Figure 2(b). The quiet time averaged TEC is shown in red colour. An observation from this Figure shows that the initial phase of the geomagnetic storm occurred during the sunrise hours on the $17^{\text {th }}$ of March and lasted for just two hours, thus having no conspicuous effect on the ionosphere. The main phase of the geomagnetic storm also occurred on the $17^{\text {th }}$ of March at between 0800UT-2000UT and was characterized by TEC enhancement (as seen at Toro and Zamb) or both TEC enhancement and depletions (as seen at Mbar, Mal2 and Dodm). This enhancements were observed to be consistent with a slightly enhanced aurora activity, $\mathrm{Kp}$ value of about 4 and the Dst attaining its minimum value of about -132 nT. Post sunset TEC enhancements (around 1800$1900 \mathrm{LT})$ were also observed at Zamb $\left(26.25^{\circ} \mathrm{S}\right)$ and Dodm $\left(16.10^{\circ} \mathrm{S}\right)$ shortly before the recovery phase of the storm began. On the average, maximum enhancement in TEC for this period, was recorded at Toro (Lat. $0.95^{\circ} \mathrm{S}$ ) with a percentage deviation of about $112 \%$ followed by $78 \%$ enhancement observed at Dodm (Lat. $16.10^{\circ} \mathrm{S}$ ) during the main phase of the storm. The recovery phase spanned over a long period, with both TEC enhancement and depletions observed at all stations. TEC enhancements were however, observed to dominate the recovery period of the geomagnetic storm at all stations.

\subsubsection{TEC response to the geomagnetic Storm event of 01 June 2013}

Figure $3 \mathrm{a}$ is a plot showing the variation of (from top to bottom): the IMF $\mathrm{Bz}, \mathrm{AE}$, Dst and Kp-index during the geomagnetic storm of 01 June, 2013. The plots span from 30 May to 03 June, 2012, while figure 3(b) is a plot of the diurnal variation of TEC for the average quiet days and the disturbed period. The initial phase of the storm began with a gradual increase in the Dst values on 31 May, starting from around 00 UT until around 0200 UT on 01 June. Around this time, a sudden and sharp decrease in Dst which is indicative of the progress in the growth of the ring current, indicating the main phase of the storm was also observed. During this time, the Dst index decreased to a value of about $106 \mathrm{nT}$ at around 0500 UT and three hours later, it decreased further, reaching a minimum Dst value of about $-116 \mathrm{nT}$ around 0800 UT. The magnitude of the Dst index is indicative of a strong geomagnetic storm with a main phase occurring during the buildup period (pre-noon period) of the ionosphere. An enhancement in the aurora electrojet $\mathrm{AE}$ (about $1300 \mathrm{nT}$ ) as well as the $\mathrm{Kp}$ index $(\mathrm{Kp}=75)$ was also observed during the main phase. The recovery phase began immediately after the Dst index attained its minimum value. The recovery period was characterised by a periodic southward - northward fluctuations of the IMF $\mathrm{Bz}$ as well as fluctuations in the $\mathrm{AE}$ index.

The initial phase of this geomagnetic storm event occurred during the night time (2200-0100 LT on $31^{\text {st }}$ May-01 June, 2013), when ionization was generally low in the ionosphere. This led to TEC depletion across all the stations. The main phase of the storm began during the post mid-night period and continued into the build-up period of ionization in the ionosphere (around 01000900 LT on 01 June, 2013). This led to TEC depletions at Toro $\left(0.95^{\circ} \mathrm{S}\right), \mathrm{Mbar}\left(10.25^{\circ} \mathrm{S}\right)$ and Mal2 $\left(12.42^{\circ} \mathrm{S}\right)$, while, both TEC depletions and enhancements were seen at Dodm $\left(16.10^{\circ} \mathrm{S}\right)$ and Zamb $26.25^{\circ} \mathrm{S}$ ). During the early part of the recovery phase, Dodm and Zamb recorded two peaks (pre-noon and post-noon peaks) of enhancement in TEC on 01 June, 2013. The first peak was recorded at about 0900UT in Dodm, with a trough (minimum daytime TEC) occurring around 1100 UT and the second peak was observed around 1400 UT. Similar observations were also made at Zamb $\left(26.25^{\circ} \mathrm{S}\right)$ with a little variation in the time of occurrence of the peaks; while the post-noon peak was observed to be higher than the pre-noon peak at Dodm $\left(16.10^{\circ} \mathrm{S}\right)$, but reverses at Zamb $\left(26.25^{\circ} \mathrm{S}\right)$. The recovery period is characterised by both TEC enhancements and depletions. Night time depletions 
in TEC were mostly observed at Toro $\left(0.95^{\circ} \mathrm{S}\right)$ during the recovery phase than other stations. Averagely, the TEC enhancement was seen to be higher during the recovery period (particularly on 02 June, 2013). Table 4 shows the details of these TEC variations during this geomagnetic storm.

Table 3. Percentage Deviation of TEC for March 17-18 Storm event

\begin{tabular}{llcccccc}
\hline S/N & Station & $\begin{array}{c}\text { Initi. Ph. } \\
(\%)\end{array}$ & $\begin{array}{c}\text { Main Ph. } \\
(\%)\end{array}$ & \multicolumn{2}{c}{$\begin{array}{c}\text { Recov. Ph. } \\
(\%)\end{array}$} \\
\hline & & & & 6 & 12 & 18 & 24 \\
& & & & Hrs & Hrs & Hrs & Hrs \\
\hline 1 & Toro & NIL & 112 & 71 & NIL & -41 & 76 \\
2 & Mbar & -42 & 18 & 13 & 27 & 14 & 33 \\
3 & Mal2 & 35 & -37 & 35 & 51 & 11 & 31 \\
4 & Dodm & 15 & 78 & 64 & -20 & 31 & 74 \\
5 & Zamb & 23 & 52 & 40 & NIL & 13 & 19
\end{tabular}

Table 4. Percentage Deviation of TEC for June 01, 2013 Storm event

\begin{tabular}{llllllll}
\hline S/N & Station & $\begin{array}{c}\text { Init. Ph. } \\
(\%)\end{array}$ & $\begin{array}{c}\text { Main Ph. } \\
(\%)\end{array}$ & \multicolumn{2}{c}{$\begin{array}{c}\text { Recov. Ph. } \\
(\%)\end{array}$} \\
\hline & & & & 6 & 12 & 18 & 24 \\
& & & & Hrs & Hrs & Hrs & Hrs \\
\hline 1 & Toro & -52 & 38 & 24 & 18 & -52 & 41 \\
2 & Mbar & -21 & NIL & -22 & 24 & 30 & 35 \\
3 & Mal2 & -35 & -32 & -28 & 32 & -50 & -34 \\
4 & Dodm & NIL & NIL & 41 & 74 & -26 & 35 \\
5 & Zamb & -25 & 40 & 65 & 89 & NIL & 32 \\
\hline
\end{tabular}

Table 5. Percentage Deviation of TEC for December 7-8 Storm event

\begin{tabular}{llllccccc}
\hline S/N & Station & $\begin{array}{c}\text { Init. Ph. } \\
\text { (\%) }\end{array}$ & $\begin{array}{c}\text { Main Ph. } \\
(\%)\end{array}$ & \multicolumn{2}{c}{$\begin{array}{c}\text { Recov. Ph. } \\
\text { (\%) }\end{array}$} & \multicolumn{2}{c}{ S/N } & \\
\cline { 7 - 9 } & & & & & 6 & 12 & 18 & 24 \\
& & & & Hrs & Hrs & Hrs & Hrs \\
\hline 1 & Toro & $17 \%$ & $15 \%$ & Nil & $17 \%$ & $-13 \%$ & $15 \%$ \\
2 & Mbar & 55 & 69 & 26 & 71 & 89 & NIL \\
3 & Mal2 & 36 & 39 & 17 & 87 & 60 & 22 \\
4 & Dodm & 39 & 13 & 22 & 32 & 29 & 24 \\
\hline
\end{tabular}

\subsubsection{TEC response to the geomagnetic Storm of December 8, 2013}

Figure 4(a) is a plot showing the variation of (from top to bottom): the IMF $\mathrm{Bz}, \mathrm{AE}$, Dst and $\mathrm{Kp}$-index during the geomagnetic storm of 08 December, 2013. The plots span from 06 - 10 December, 2013, while figure 4(b) is a plot of the diurnal variation of TEC for the average quiet days and the disturbed period. Figure 4(a) shows that the IMF Bz was southward from around 1400 UT on December 06, until around noon on December 07, when it experienced a sudden northward turning. This triggered the initial phase of the storm with a gradual increase in the Dst index to a maximum value of about $20 \mathrm{nT}$. Thereafter, the IMF Bz began a periodic north - south fluctuations, leading to an enhancement in the $\mathrm{AE}$ index and an increase in the growth of the ring current, thus indicating the main phase of the geomagnetic storm. This was accompanied by a decrease in the Dst index to a value of about $-55 \mathrm{nT}$ and thereafter, to a minimum value of about - $70 \mathrm{nT}$ on December 08, while Kp and AE indices recorded their maximum values of about 60 and $1750 \mathrm{nT}$, respectively, day after which the Dst began to increase gradually, signifying the end of the main phase and the beginning of the recovery phase of the storm. A clear case, TEC enhancement was seen across all the stations during the main phase of the storm except at ZAMB where the enhancement is quite insignificant compared to other stations. Toro $\left(0.95^{\circ} \mathrm{S}\right)$ recorded an enhancement of about 15
TECU on December 8 while a prominent secondary peak were observed at Mbar $\left(10.25^{\circ} \mathrm{S}\right)$, Mal2 $\left(12.43^{\circ} \mathrm{S}\right)$ and Dodm $\left(16.10^{\circ} \mathrm{S}\right)$. The maximum TEC enhancement occurred during post noon period of the recovery phase at Mbar $\left(10.25^{\circ} \mathrm{S}\right)$ as shown in Table 3. This station also recorded maximum enhancement in TEC during both the main and recovery phases and the lowest values for the two phases occurred at Toro $\left(0.95^{\circ} \mathrm{S}\right)$, most of which fall below $20 \%$ (Table 5).

\section{Discussion}

Generally, the ionospheric TEC increases as the intensity of solar radiation increases, this usually is caused by increase in ionization in the ionosphere and was seen to begin at sunrise (0600 LT) at all stations. A closer look at the quiet time profiles in this study reveal that; although ionization begins at the same time at all stations; higher TEC values were recorded during the buildup period at Toro $\left(0.95^{\circ} \mathrm{S}\right)$, thus suggesting a stronger rate of ionization around the geomagnetic equator. All the stations used for this study are within the equatorial and low latitude region of the southern hemisphere and therefore, one could observe a movement of ionization away from the equatorial region with increase in solar radiation. This is evident with the occurrence of the daytime TEC peaks at Mbar $\left(10.25^{\circ} \mathrm{S}\right)$ and Mal2 $\left(12.43^{\circ} \mathrm{S}\right)$. Also, the high noon time values recorded away from the equator around noon is a result of EIA phenomenon which transport the ionization from the geomagnetic equator towards the lowlatitudes. The movement of ionization in the equatorial and low latitude has been attributed to the combined forces of zonal electric and the earth's magnetic (ExB) fields (Adeniyi, 1986; Radicella and Adeniyi, 1999; Anderson et al, 2004 and Yizengaw et al, 2012). When the zonal electric field lines (E) acts on ionospheric plasma with the earth's magnetic field (B) which is about horizontal around the equator, it results in drift ionization otherwise known as vertical plasma drifts. This is elaborately discussed by Anderson et al. (2002).

The occurrence of double peaks of ionization during the day time, with depletion in TEC occurring around noon time, otherwise known as the noon bite-out (Ross, 1966; Olatunji, 1967; Rufenach et al., 1968; Rastogi et al., 1973; Rastogi et al., 1979; Klobuchar and Rastogi, 1988; Lee et al., 2010, Radicella and Adeniyi, 1999), which usually occur as a result of ionospheric dynamics; is known to be a prominent feature of the equatorial ionosphere. This feature is however not conspicuous at all the stations considered in this study. A feature of nighttime enhancement of TEC at low-latitudes (during and after prereversal enhancement of the zonal electric field) is observed at equatorial and low-latitude stations. This nighttime enhancement has been attributed to the reverse fountain effect and the movement of ionization crest towards the equator (Yadav et al., 2020).

The results of the geomagnetically disturbed period show both TEC enhancements and depletion at all the stations. It is generally known that the TEC morphological features of the equatorial and low latitude ionosphere are mostly influenced by the changes in the zonal electric field. Studies of Raghavarao and Sivaraman, (1973) and Fejer, (1981) had shown that; a decrease in the eastward electric field during the sunlit hours can result into an enhancement in the equatorial TEC during geomagnetic storms. On the other hand, an increase in the eastward electric field can lead to a decrease in the electron density of the equatorial ionosphere and the equatorial anomaly enhancement. However, neutral wind composition changes are also known to take place in the equatorial region during geomagnetic storm events (Prolss, 1982, 1993) even though the occurrence is more prominent at high, mid and low latitudes. 


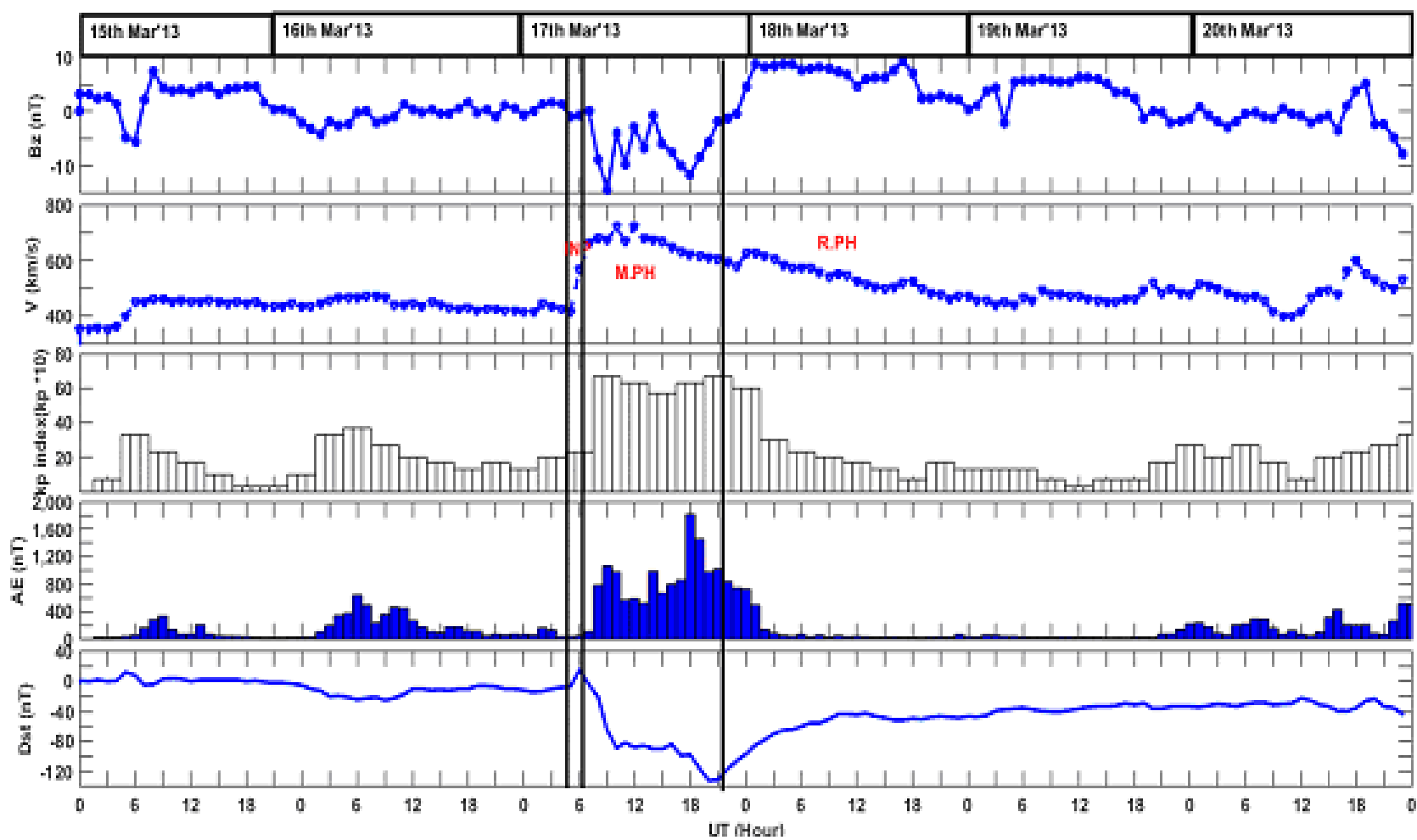

Figure 2a Diurnal Variation of IMF Bz, AE, Dst and Kp-index during the geomagnetic storm of 17-18 March, 2013

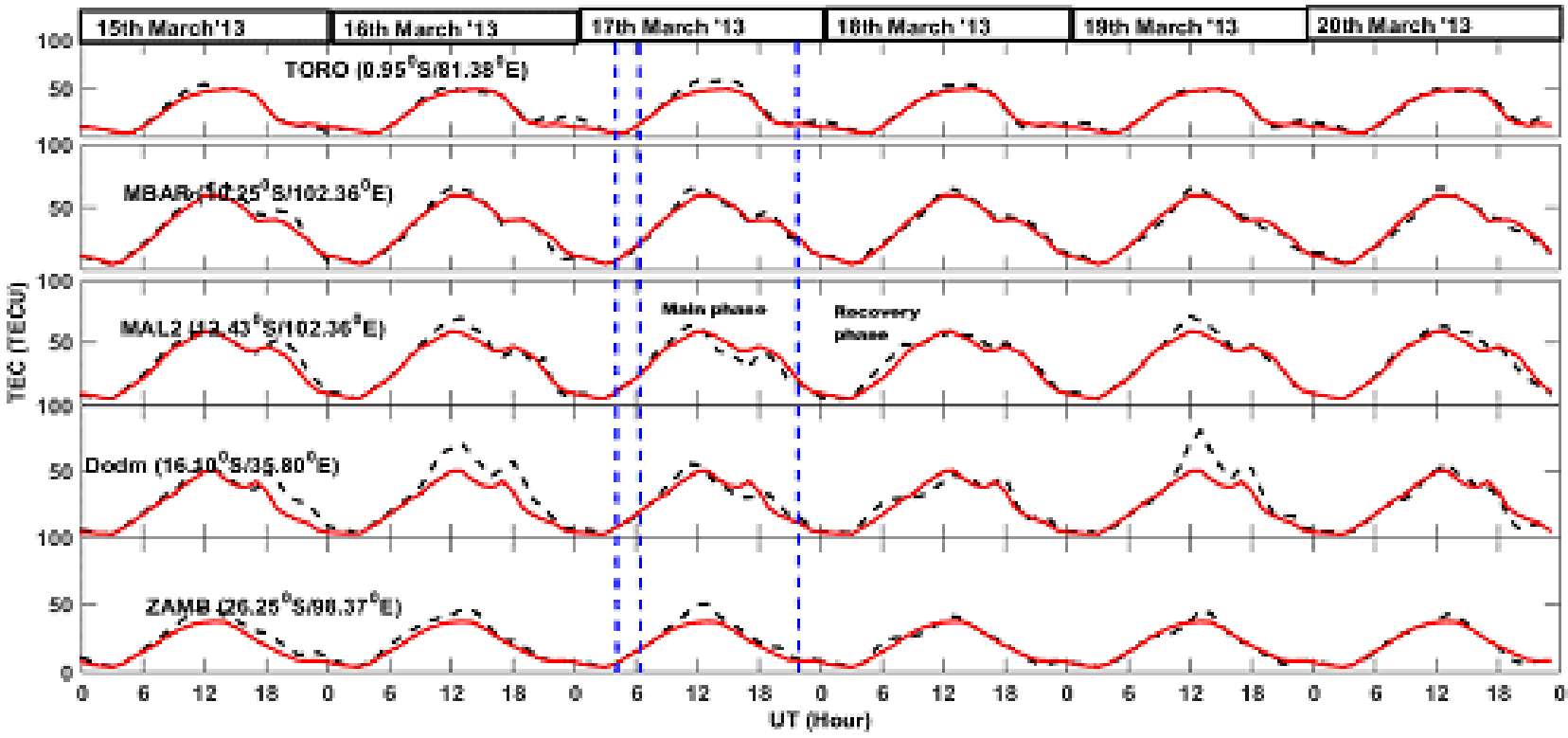

Figure 2b Diurnal Variation of TEC at Toro, Mbar, Mal2, Dodm and Zamb during the geomagnetic storm of March 17-18, 2013. Red curves and black dashed line indicates the quiet time averaged and the storm time variation of TEC, respectively.

Adeniyi, (1986), has earlier shown that the motion of plasma at the equatorial and low latitude is basically controlled by the combine action of the horizontal component of the magnetic field and the equatorial electric field. Variations in the electric field have been reported to be responsible for the response of the ionosphere at the equatorial and low latitudes during geomagnetic storms (Onwumechili et al., 1973; Mikhailov et al., 1994; Fejer, 2002;Fuller-Rowell, 2002; Tsurutani et al., 2004;Yizengaw and Moldwin, 2005). These variations sometimes occur as a result of the prompt penetration of electric field and the disturbance dynamo electric field (Yizengaw and Moldwin, 2005; Sastri, 2005; Fejer and Sherliess, 1997). The prompt penetration of electric fields are known to enhance the existing fountain effect when the interplanetary magnetic field (IMF Bz) turns southward.
This can cause changes in the ionospheric electron density and the dynamics of the ionosphere (Buosanto, 1999), that will either lead to increase or decrease in the ionospheric TEC, depending on the time of occurrence of the geomagnetic storm, its nature, as well as the latitude of observation.

The TEC enhancement observed during the daytime period on June 01, show three different double peaks at Dodm, one at the initial phase of the storm, the second one was observed during the main phase while the third double peak was observed during the recovery phase of the storm. Also two double peaks were seen during the recovery phase at Mal2 while another two peaks of about the same magnitude observed at Zamb during the main phase could be attributed to the westward electric field associated with the southward orientation of the IMF Bz. The westward 
electric field could be generated when the IMF Bz changes its orientation from south to north (Kelley et al., 1979). Prompt penetrating electric field is generally eastward during the main phase of a geomagnetic storm in the day period but westward during the recovery phase. The two peaks at Zamb suggest the effects of both Prompt Penetration and Disturbance Dynamo (DD) electric fields, as suggested by Abdu et al. (1991, 2007); Spiro et al, 1998; Fuller-Rowell et al, 1996, 1994. The rise in TEC observed on June 02 was seen to vary with the increase in latitude peaking at Dodm. The commencement of this enhancement around 0800 UT was observed to be simultaneous with the southward turning of the IMF Bz with a threshold of about $3 \mathrm{nT}$. This is indicative of the enhancement of the fountain effect by the prompt penetration electric fields during the recovery period of the geomagnetic storm.

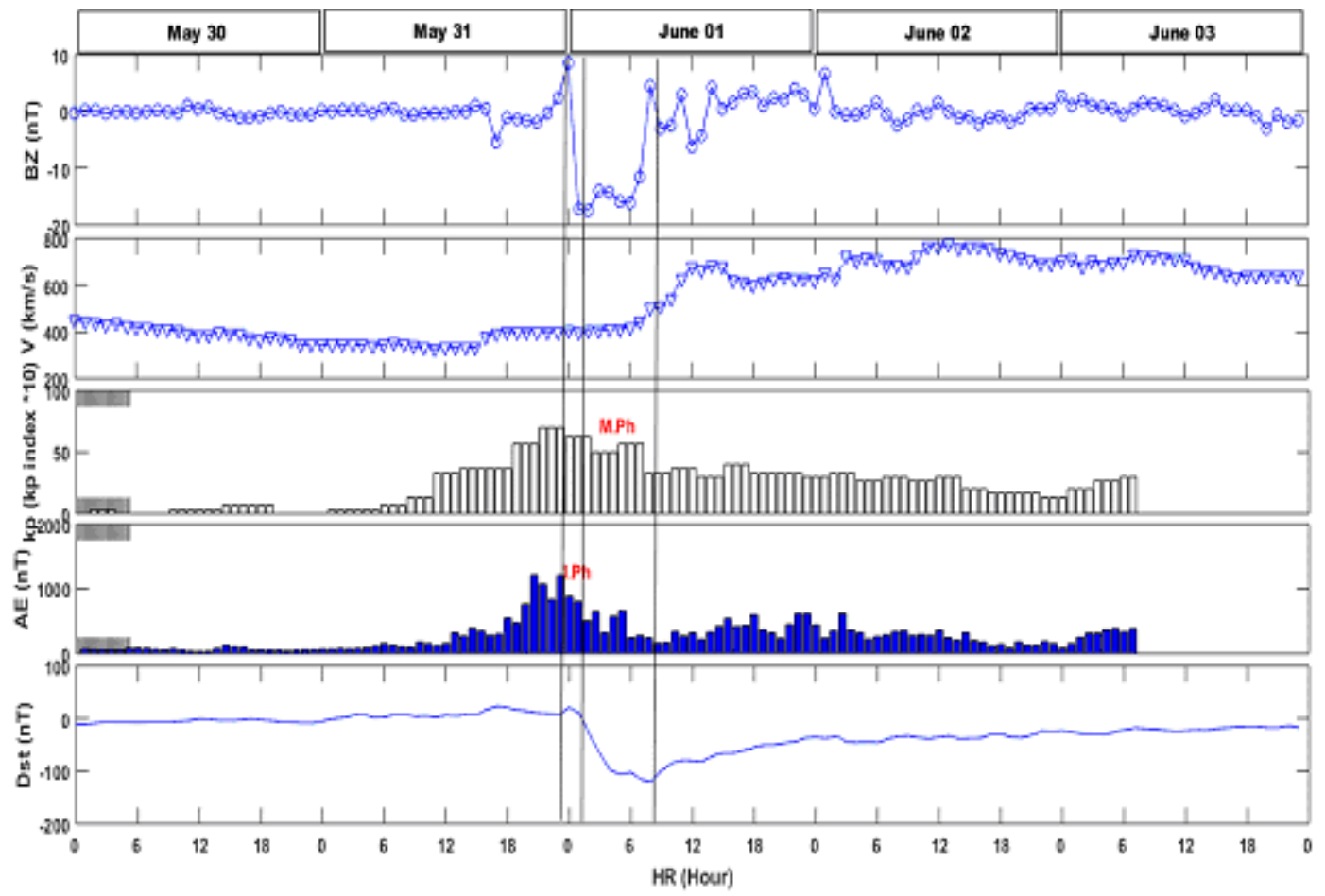

Figure 3a Diurnal Variation of IMF Bz, AE, Dst and Kp index during the geomagnetic storm of June 01, 2013

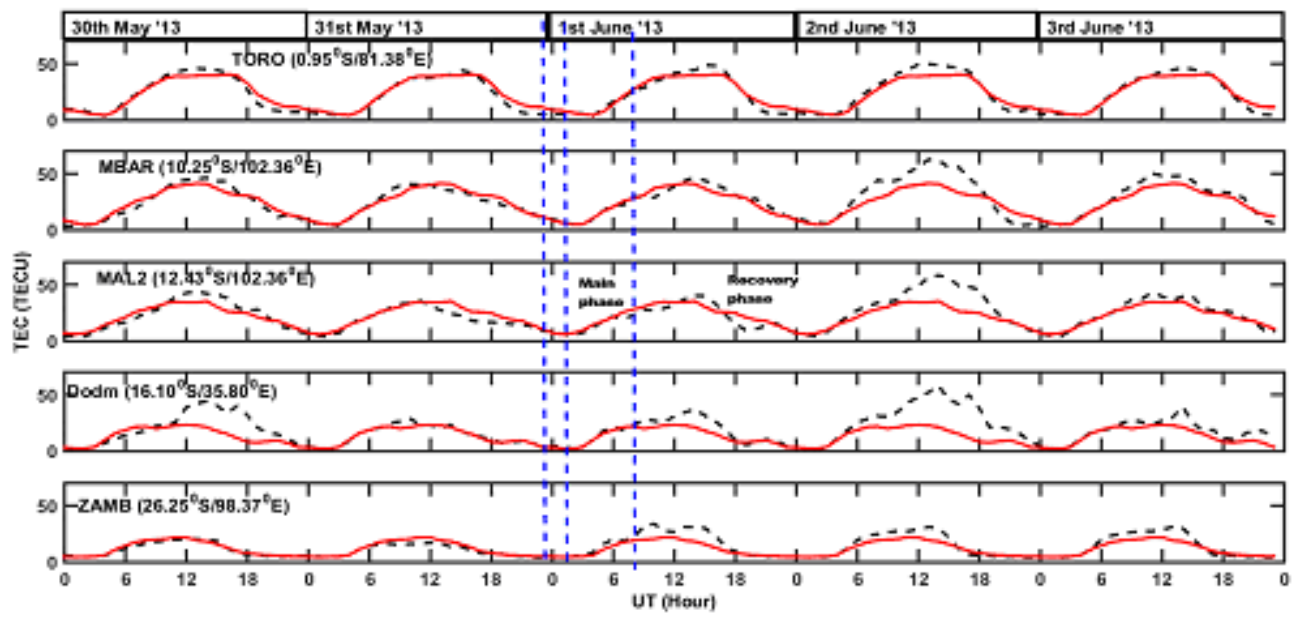

Figure 3b Diurnal Variation of TEC at Toro, Mbar, Mal2, Dodm, and Zamb during the geomagnetic storm of June 01, 2013. Red curves and black dashed line indicates the quiet time averaged and the storm time variation of TEC, respectively.

The maximum enhancement in TEC observed mostly during the recovery phases of the geomagnetic storms as observed in some stations are consistent with the findings of Adeniyi (1986), Lastovicka (1996), Mansilla (2004), Burns et al., (2007), Adebesin (2008), Joshua et al., (2011, 2013a); Adebiyi et al. (2012), Alagbe (2012), Olawepo and Adeniyi (2012), Olawepo et al., (2014), Adebiyi et al. (2014); Joshua et al. (2014) etc. The daytime enhancements in the TEC observed in this study could be attributed to the increase in ionization as a result of the combined actions of the equator ward movement of the neutral winds, joule heating dissipation in the high latitude polar region, and the pressure gradient driving the neutral wind (Buosanto 1999; Lu et al, 2008; Olawepo et al., 2015). On the other hand, the night time enhancements observed could be attributed to the changes in neutral composition and possibly an inflow of the electrons from the protonsphere (Adeniyi, 1986). However, there is no specific pattern observed in terms of the TEC increases or decreases with the change in latitude during geomagnetic storms, except during the recovery period of June 01 , storm event. The TEC responses to the initial phases of the storm shows TEC enhancement at all stations during the March and December storms (Table 3 and 5) 
and TEC depletions during the June geomagnetic storm. Adeniyi (1986), has earlier shown that during the initial phase of a geomagnetic storm, the increase in the $\mathrm{H}$ component could enhance the EXB force and consequently the drift of ionospheric electron density away from the equatorial region. Averagely, the effect of the geomagnetic storm appears to be stronger around the geomagnetic equator during all phases of the March geomagnetic storm and varies during the other geomagnetic storm events.
TEC depletions recorded during the main and the recovery phase of the geomagnetic storms are consistent with the works of Danilov and Lastovicka (2001), Yizengaw et al. (2005), Olawepo and Adeniyi (2012), Shimeis et al. (2012), Joshua, 2014, etc; and it could be as a result of the imbalance in the neural composition in the ionosphere. It has been shown that an increase in the mean molecular mass due to upwelling leads to a decrease in the total electron content in the ionosphere (Buosanto, 1999).

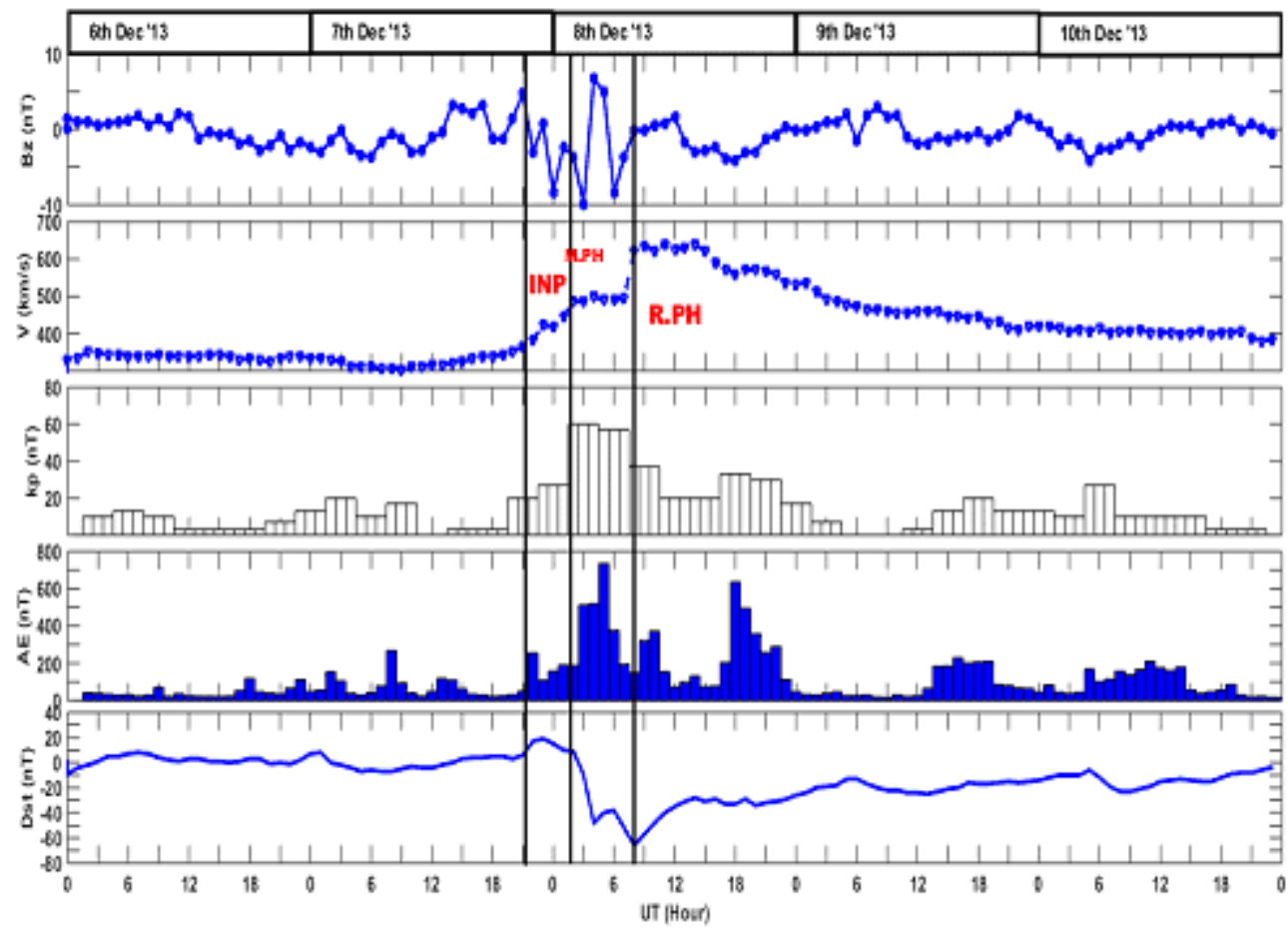

Figure 4a Diurnal Variation of IMF Bz, AE, Dst and Kp-index during the geomagnetic storm of Dec 08, 2013

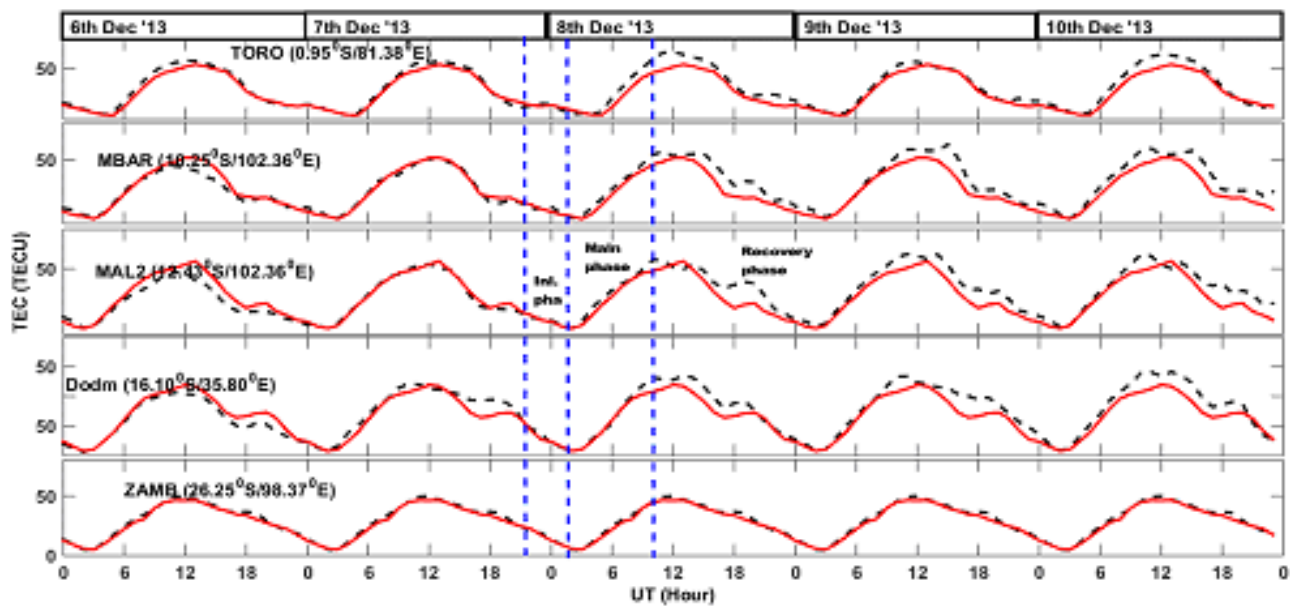

Figure 4b Diurnal Variation of TEC at Toro, Mbar, Mal2, Dodoma and Zamb during the geomagnetic storm of Dec 08, 2013. Red curves and black dashed line indicates the quiet time averaged and the storm time variation of TEC, respectively.

\section{Conclusion}

The response of the five African equatorial and low latitude stations to three geomagnetic storm events of March 17-18, June 01, and December 7-8, 2013 has been studied in terms of the variation in TEC. We have also made use of interplanetary magnetic field (IMF) Bz, solar wind speed (Vx), magnetic indices such as the aurora electrojet index (AE), planetary (Kp) index, and the Disturbance storm time (Dst) index. Prominent features of this study includes;

The occurrence of the pre-sun rise minimum for all stations occurring at around $0500 \mathrm{LT}$; higher ionization during the build- up/pre-noon period (0500-1100 LT) at Toro $\left(0.95^{\circ} \mathrm{S}\right.$ geomagnetic latitude), during the three months. While the daytime TEC peak values were recorded at Mbar and Mal2 during the post-noon period (1300-1600 LT), the minimum daytime values were mostly recorded at Zamb.

Lower rate of ionization in the month of June for all the stations with a difference that is greater than 10 TECU when compared with those observed in March and December. A clear case of night time enhancement was observed at Mbar and Mal in the month of March and June. Higher TEC night time values (TEC>30 TECU) were mostly recorded in these two stations. 
During geomagnetic storms, both TEC enhancements and depletions were observed, depending on the time of occurrence and the characteristics of the geomagnetic storm. However, TEC enhancements were most prominent during both the main and recovery phases of the storm. In some cases higher peaks of ionization were observed during the recovery phase. This was attributed to the motions of plasma at the equatorial and low latitude which is basically controlled by the combined action of the horizontal component of the magnetic field and the equatorial electric field (E x B force).

Maximum enhancement in TEC was recorded at an equatorial station, Toro (Lat. $0.95^{\circ} \mathrm{S}$ ) with a percentage deviation of about $112 \%$ followed by $78 \%$ enhancement observed at Dodm (Lat. $16.13^{0} \mathrm{~S}$ ) during the main phase of the March 17-18 storm.

TEC enhancement in the form of a well- defined double peak of ionization was observed during the main phase of strong geomagnetic storm of June 01, 2013 event particularly at Dodm $\left(16.10^{\circ} \mathrm{S}\right)$ and $\mathrm{Zamb}\left(26.25^{\circ} \mathrm{S}\right)$.

These enhancements were attributed to the effect of the prompt penetration electric field and the enhanced action of the equatorial fountain effect. In addition, the equatorward neutra wind can also play a role to enhance the TEC at low-latitudes as the equatorward neutral wind increases the ionization by moving the layer up to higher altitude where recombination effect is less.

\section{Acknowledgements}

The authors will like to acknowledge the National Space Research and Development Agency/Centre for Satellite Technology Development, Nigeria for the support given throughout the course of this research work. The World Data centre for geomagnetism (WDC), Kyoto ,Japan (website: http://wdc.kugi.kyoto-u.ac.jp/cgi-bin/qddays-cgi ) and the African Geodetic Reference frame (AFREF) networks for making the data used for this work readily available online. The authors will also like to acknowledge the efforts of the Scientific Committee on Solar-Terrestrial Physics (SCOSTEP), the International Centre for Theoretical Physics (ICTP) for their support in one way or the other throughout the course of this study.

\section{References}

Abdu, M. A., Sobral, J. H. A., de Paula, E. R. and Batista, I. S., 1991. J. of Atm and Sol. Terr. Phy. 53, 757- 771.

Abdu, M. A., Maruyama, T., Batista, I. S., Saito, S., and Nakamura, M.: 2007. J. Geophys. Res. 112, A10306,

Adebesin, B.O., Chukwuma, V.U.: 2008, ActaGeod. Geophys. Hung. 43 (1), 1-15.

Adeniyi, J.O.: 1986, J. Atmos. Terr. Phys. 48 (8), 695-702.

Adeniyi, J.O., Joshua B.W.: 2014, J. Atms. And Sol. Terr. Phys., $120,102,-110$.

Adeniyi, J.O., P.H., Doherty, Oladipo O.A. and Bolaji, O.: 2014, Radio Sci., 49, 1245- 1253.

Adeniyi, J.O., Olawepo, A. O., Obrou, O. K.: 2010, Centre Point (Science Ed) 16 7-14

Adewale, A. O., E. O. Oyeyemi, A. B. Adeloye, C. N. Mitchell, J. A. R. Rose, and Cilliers P. J.: 2012Radio Sci., 47, RS2011,

Akasofu, S.-I.: 1995, Planet space Sci., 13, 297.

Alagbe, G. A.: 2012, J. Phys. Sci. Innov. 4, 5- 12.

Anderson, D., A. Anghel, J. Chau, and Veliz 0.: 2004, Space Weather, 2, S11001.

Anderson, D., A. Anghel, K. Yumoto, M. Ishitsuka, and Kudeki E.: 2002, Geophys. Res. Lett., 29(12), 1596.

Appleton, E.V. (1946). Two anomalies in the ionosphere, Nature, 157, 691-693.

Balan, N., K. Shiokawa, Y. Otsuka, T. Kikuchi, D. Vijaya L., S. Kawamura, M. Yamamoto, and Bailey G.J.: 2010., J. Geophys. Res., 115, A02304,

Balan, N., Bailey, G. J.: 1995, J. of Geophys.Res. 100, 21421Bounsanto, M.J.: 1999, Space Sci. Rev. 88, 563-601.

Burns, G., Solomon, S.C., Wang, W., Killeen, T.L.: 2007, J. Sol. Terr. Phys. 68 (1-2), 77-85.

Campbell, W. H.: 2003, Introduction to geomagnetic field (Second Edition), Cambridge

University Press, New York, ISBN978-0-521-82206-0, pp 65-90.
Ckraborty, S. K., Hajra, R.: 2009, Ann Geophys., 27, 93-105

DaGupta, A., A. Paul A. and Das A.: 2007, Indian J. of Radio and Space Physics, Vol 36, 278-29.

Danilov, A.D., Lastovicka, J.: 2001, Int. J. Geomag. Aeron. 2 (3), 209-224.

Danilov, A.D., Belik, L.D., Mirmovich, E.G.: 1985. Geomag. Aeron. 25, 768- 772 (in Russian).

Dungey, J. W.: 1961, Phys. Rev. Lett., 6, 47-48.

Fejer, B. G., Scherlies L.: 1998; Geophysical Research Letters, Vol. 25, NO.16, 3071-3074

Fejer, B.G., 2002. Low latitude storm time electrodynamics. J. Atmos. Sol. Terr. Phys. 64, 1401.

Fuller-Rowell, T. J., Codrescu, M. V., Moffett, R. J., and Quegan, S.: 1994; J. Geophys. Res, 99, 3893- 3914.

Fuller-Rowell, T. J., Codrescu, M. V., Rishbeth, H., Moffett, R. J., and Quegan, S.: 1996. J.Geophys. Res., 101, 2343 - 2353

Fuller-Rowell, T.J., Millward, G.H., Richmond, A.D., Codrescu, M.V.: 2002. J. Atmos. Solar Terr. Phys. 64, 1383-1391.

Gonzalez, W. D., and Tsurutani B.T.: 1987, Planetaryand Space Science, 35, 1101- 1109.

Handerson, S.B., Swenso, C.M.: 2005, J. of Geophys. Res. 110, A11306.

Hanso, W.B., Moffet, R.J.:1996. J of Geophys. Res.71, 5559-5572.

Jakowaski, N.: 1996, European Geophysical Society, 371-390.

Joshua, B., Adeniyi, J.O., Adimula, I.A., Abbas, M., Adebiyi, S.J.: 2011, World J. Young Res. 1 (5), 71-78.

Joshua, B.W., Adeniyi, J.O., Adimula, I.A., Oladipo, O.A., Olawepo, O.A., Adebiyi, S.J.: 2013a. : 2010, J. Adv. Space Res. 53, 219-225.

Joselyn J.A., Tsurutani B.T.:1990, Eos Trans, AGU, 71, 1808.

Kamide, Y., Baumjohann, W., Daglis, I.A., Gonzalez, W.D., Grande, M., Joselyn, J.A., McPherron, R.L., Phillip, J.L., Reeves, E.G.D., Rostoker,G., Sharma, A.S., Singer, H.J., Tsurutani, B.T., Vasyliunas, V.M.: 1998, J. Geophys. Res. 103 (A8), 17705-17728.

Klobuchar, J. A., and Rastogi R.G.: 1988, Radio Sci., 23, 292-298,

Lastovicka, J.: 1996: J. Atmos. Sol. Terr. Phys. 66 (12), 831-843.

Lee, C. C., Y. J. Chuo, and Chu F.D.: 2010, J. Atmos. Sol. Terr. Phys., 72, 207-212.

Loewe, C.A., and Prolss, G.W.: 1997, J.OfGeophys. Res., Vol. 102, No. A7, 14,209-14,213.

Lu, G., L. P. Goncharenko, A. D. Richmond, R. G. Roble, and Aponte N.: 2008, J. Geophys. Res., 113.

Lu, G., Pi, X., Richmond, A.D. \& Roble, R.G.: 1998, Geophys. Res. Letters, 25, 253-256.

Mansilla, G.A.: 2004, J. Atmos. Sol. Terr. Phys. 66 (12), 10851091.

Meloni A., P. De Michelisand Tozzi,R.: 2005; Mem.S.A.It. Vol 76,882

Mendillo, M.:2006, American Geophysical Union, v. 44, n. 2005RG000193, pp. 47.

Mikhailov, A.V., Forster, M.,Skoblin, M.: 1994. Ann. Geophys. 12, 226-231

National Research Council (NRC) Report, 2008. The National Academies Press, Washington DC, USA

Oladipo, O.A., SchülerT.: 2012, Adv.SpaceRes.50,1204-1212.

Olatunji, E. O.: 1967, J. Atmos. Terr. Phys., 29, 277-285.

Olawepo, A.O., Adeniyi, J.O.: 2012, Afr. Rev. Phys. 7, 277, 0031.

Olwendo, O.J., Baki C. M. and Doherty, P.: 2012, J. Atmos.Sol. Terr. Phys., 84-85, 52-61.

Onwumechili, A., Kawasaki, K., Akasofu, S.I.: 1973. Planet Space Sci. 21, 1-8.

Rabiu, A.B., Adewale, A.O., Abdulrahim, R. B., Oyeyemi, E. O.: 2014. Advances in Space Research. 53, 1290-1303

Rastogi, R. G., G. Sethia, H. Chandra, M. R. Deshpande, K. Davies, and Murthy B.S.: 1979, J. Atmos. Terr. Phys., 41, 561-564.

Rastogi, R. G., R. P. Sharma, and Shodhan V.: 1973, Planet. Space Sci., 21, 713-720,

Ross, W. J.: 1966, J. Geophys. Res., 71, 3671-3676.

Rufenach, C. F., V. T. Nimit, and Leo L.E.: 1968, J. Geophys. Res., 73, 2459-2468,

Radicella, S. M., and Adeniyi J.0.: 1999, Radio Sci., 34, 11531163.

Tsurutani, B.T., and Gonzalez W.D.: 1997; Geophys.,Monogr.ser., vol 98, pg 77.

Radicella, S. M., and Adeniyi J. 0.: 1999; Radio Sci., 34(5), 11531163. 
Rakhee, M., Shivalika, S., Shweta, M., Gwal, A.K., 2010. J. India Geophys. Union 14 (1), 47-56.

Reeve W.D.: 2010; Geomagnetism tutorial, reeve observatory anchorage, Alaska USA. 61630N:262.89E Iss. 1.0. Retrieved from <www.reeve.com>

Rostoker, G., and Falthamma, C.G.: 1967, J. Geophy.Res., 72, 5853.

Sastri, J.H., 2006. Effect of magnetic storms and sub-storms on the low latitude/ equatorial ionosphere. ILWS Workshop, 2006, GOA

Shimeis, A., Fathy, I., Amory-Mazaudier, C., Fleury, R., Mahrous, A.M., Yumoto, K., Groves, K.: 2012, J. Geophys. Res. 117, A07309.

Yadav., S., Choudhary R.K., Jyoti K., Surendra S., Shreedevi P. R., Tarun. K. P. (2020),

Journal of Geophysical Research: Space Physics, e2019JA027286, DOI: 10.1029/2019JA027286

Shweta, S., Galav, P., Dashora, N., Dabas, R.S., Pandey, R.,: 2012, J. Atmos. Sol. Terr. Phys. 75-76, 133-140.

Spiro, R.W., Wolf, R.A., Fejer, B.G.: 1998. Annales of Geophysicae 6, 39-50.

Taylor, J.R., M. Lester, and Yeoman T.K.: 1994, Ann. Geophys. 12, 612.

Tsurutani, B.T., Gonzalez, W.D.: 1995, Geophys. Res. Lett. 22, 663.

Tsurutani, B., Mannucci, A., lijima, B., Abdu, M.A., Sobral, J.H.A., Humberto, A., Gonzalez, W., Guarnieri, F., Tsuda, T., Saito, A., Yumoto, K., Fejer, B., Fuller- Rowell, T.J., Kozyra, J., Foster, J.C.,Coster, A., Vasyliunas, V.M.: 2004. J. Geophys. Res. 109, A08302.

Wang, X., Sun,Q., Eastes R., Reinisch, B. and Valladares, C.E.: 2008, J. of Geophy. Res, 113, A11308.

Yizengaw, E., Essex, E.A., Moldwin, M.B.: 2005, Ann. Geophys. 23, 707-721.

Yizengaw, E., Zesta, E., Moldwin, M.B., Damtie, B., Mebrahtu, A., Valladares, C.E., and Pfaff, R.F.: 2012, Journal of Geophys. Res. 117, A07312. 